\title{
Comparison of Students' Perceived Mastery and Teachers' Perceived Competencies in Different Concepts in General Chemistry
}

\author{
Welyn Rentillo-Co \\ Associate Professor, School of Science and Technology, Centro Escolar University, Manila, Philippines \\ *Corresponding Author: Welyn Rentillo-Co, Associate Professor, School of Science and Technology, \\ Centro Escolar University, Manila, Philippines
}

\begin{abstract}
The purpose of the study is to compare the perceived mastery of the students and the perceived competencies of teachers in the different concepts of General Chemistry. The results of the study will allow teachers to self-assess their own performance against the Competency Standards in order to identify areas of strength, as well as areas that need to be developed further for them to function more effectively as facilitators of learning. The study utilized a descriptive-comparative research as the design of the study. Questionnaires were administered to students and teachers to gather the data and were analyzed using mean, standard deviation and t test. Results revealed that the students showed a high level of mastery in almost all General Chemistry concepts except, on chemical kinetics and equilibrium, and on nuclear processes. On the other hand, faculty members need to improve their teaching competency in some areas in teaching chemistry, particularly, on nuclear processes. A difference in the perceived mastery and perceived competencies in different concepts in general chemistry among students and teachers.
\end{abstract}

Keywords: Perceived Mastery, Perceived Competencies, General Chemistry

\section{INTRODUCTION}

It is often said that no nation can rise above the quality of education of its citizenry. And, by extension no educational system can rise above the quality of its teachers. The quality of teacher determines the quality of human resources in all other sectors of labor market. It underscores the significance of the quality of teacher education programs. The question then is what is teaching and who is a teacher? Teaching is a systematic, rational and organized process of transmitting knowledge, attitudes and skills in accordance with professional principles. A teacher is a person who has undergone approved professional training in education at appropriate levels capable of imparting knowledge, attitudes, and skills to the learner ${ }^{[1]}$.

A critical challenge for today's tertiary education institutions is to develop and implement comparisons and learning practices that foster and nurture student competencies reflective of the complexities and tasks relevant to industries operating in a global environment. Tertiary institutions are expected to provide students with a skill-base which allows them to learn, retain and disseminate information more efficiently and effectively through critical thinking, problem solving, analysis, synthesis of ideas and the drawing inferences and conclusions ${ }^{[2]}$.

Comparisons of student's subject mastery and teachers' attitudes, proficiency and effectiveness in the primary and post-primary institutions today suggest the abysmal state of teacher's preparation in training institutions. This by extension is responsible for the falling and failing standard of education being experienced. The causal factors range from contingency effects of external factors around the school system to the effects of the interplay of other units within the school system itself amongst other things. A trained teacher should be thoroughly and rigorously groomed in all techniques of teaching and all aspects of pedagogy, whether he has been on practice or not, since it is not sufficient to organize a brush up program for a quack nurse, doctor or lawyer to make a professional out of him [1].

The researcher believes that it is important to look into the student's performance in relationship with teaching competency in chemistry in the tertiary level. Thus, the researcher looked into how the 
designed and given curriculum for tertiary chemistry subject for the teacher's competencies interplay with the student's performance inside the classroom. Moreover, it sought to investigate the comparison of students' perceptions of their mastery of chemistry concepts and teachers' perceptions of their competencies in teaching General Chemistry based on the domains provided in the study.

The results of the study will become the basis of proposed modules on instructional strategies. This is viewed in the rationale that comparisons of perceptions allow teachers to self-assess their own performance against the Competency Standards in order to identify areas of strength, as well as areas that need to be developed further for them to function more effectively as facilitators of learning.

\section{MATERials AND Method}

\subsection{Study Participants}

In conducting this descriptive-comparative research, teachers $(n=25)$ and students $(n=1407)$ in a selected University were given questionnaires. Specifically, students who had taken General Chemistry regardless of course and faculty members who are teaching chemistry were included.

\subsection{Sampling Technique}

The study participants were selected through purposive sampling and stratified random sampling. All of the teachers who are teaching General Chemistry were included while the second year students were selected and divided in the three campuses of the selected university.

\subsection{Statistical Treatment of Data}

The data gathered were analyzed using weighted mean and standard deviation. In addition, $t$ test was used to determine the difference between the perceived mastery and perceived competencies of students and teachers in different concepts in General Chemistry.

\subsection{Ethical Consideration}

The researcher complied with the Institutional Ethics and Review Board (IERB) before conducting the study. Anonymity and confidentiality were observed in all levels of data collection.

\section{RESUltS}

\subsection{Students' Perceived Mastery and Teachers' Perceived Competencies in the General Chemistry Concepts}

Table 1 shows the the students' perceived mastery and teachers' perceived competencies regarding the General Chemistry concepts. The results showed that nine out of the ten (10) main topics in Chemistry acquire an interpretation of "much competent" to the teachers while eight out of the ten topics to thestudents achieved a verbal interpretation of to a large extent in the three campuses. It reflects that the concepts imparted by the teachers were well-understood and learned effectively by the students

Table1. Perceived Mastery and Perceived Competencies of Students and Teachers in the General Chemistry Concepts

\begin{tabular}{|c|c|c|c|c|}
\hline General Chemistry & \multicolumn{2}{|c|}{ Students' Mastery } & \multicolumn{2}{c|}{ Teachers' Competencies } \\
\hline $\begin{array}{c}\text { Concepts } \\
\text { Matter: its composition and } \\
\text { properties }\end{array}$ & 3.88 & Large extent & 4.0 & Much competent \\
\hline $\begin{array}{c}\text { Atoms and molecules } \\
\text { Chemical bonds }\end{array}$ & 3.74 & Large extent & 3.94 & Much competent \\
\hline $\begin{array}{c}\text { Conservation of matter and } \\
\text { stoichiometry }\end{array}$ & 3.66 & Large extent & 3.75 & Much competent \\
\hline Gases, liquids and solids & 3.67 & Large extent & 3.88 & Much competent \\
\hline Acid, bases and salts & 3.88 & Large extent & 4.13 & Much competent \\
\hline Solutions & 3.57 & Large extent & 3.81 & Much competent \\
\hline Chemical thermodynamics & 3.69 & Large extent & 3.87 & Much competent \\
\hline Chemical kinetics and equilibrium & 3.35 & Moderate extent & 3.50 & Much competent \\
\hline Nuclear processes & 3.19 & Moderate extent & 3.43 & Moderately competent \\
\hline
\end{tabular}




\subsection{Comparing the Student's Perceived Mastery and Teachers' Perceived Competencies in the General Chemistry Concepts}

Table2. Graduates' Performance in the Different Subtests of the Medical Technology Licensure Examination in Three Curriculum Years

\begin{tabular}{|l|l|l|l|}
\hline General Chemistry Concepts & t value & p value & Interpretation \\
\hline Matter: its composition and properties & -4.37 & $* 0.000$ & Significant \\
\hline Atoms and molecules & -4.35 & $* 0.000$ & Significant \\
\hline Chemical bonds & -4.12 & $* 0.000$ & Significant \\
\hline Conservation of matter and stoichiometry & -5.08 & $* 0.000$ & Significant \\
\hline Gases, liquids and solids & -3.97 & $* 0.000$ & Significant \\
\hline Acid, bases and salts & -3.24 & $* 0.001$ & Significant \\
\hline Solutions & -4.10 & $* 0.003$ & Significant \\
\hline Chemical thermodynamics & -2.88 & $* 0.004$ & Significant \\
\hline Chemical kinetics and equilibrium & -3.30 & $* 0.001$ & Significant \\
\hline Nuclear processes & 3.14 & $* 0.002$ & Significant \\
\hline
\end{tabular}

*p value is significant at 0.01 levels

Based on the data, the perception of the teachers is very significant to the perception of the students regarding the General Chemistry concepts as shown in Table2. It implies that there is a significant difference between the students' and teachers' perceptions in almost all of the General Chemistry concepts. This means that the faculty perceived themselves very competent whereas, the students saw themselves as not competent as regards to mastery. There is a discrepancy in the students' and teachers' perceptions on the mastery and competencies which are an indication that the teachers need to improve their instructional strategies.

\section{DISCUSSION}

The study was conducted to determine the perceived mastery of the students and the perceived competencies of the teachers in different concepts of General Chemistry and to compare the mastery and competencies of the students and teachers. Based on the students' perceived mastery of concepts, most of the indicators were rated as "large extent' and the teachers' perceived competencies were rates as "much competent'. According to Glass and Smith ${ }^{[3]}$, teacher education coursework had a positive effect on student learning and was sometimes more influential than additional subject matter preparation. Furthermore, Olatunde ${ }^{[4]}$ reported that teachers' attitude towards teaching significantly predicted students' attitude as well as achievement in Mathematics. Also, De Chavez ${ }^{[5]}$ added that teacher-educators and teaching competence contributes to supplementary development of quality education effectiveness in the field of teaching.

Teaching standards are the essential foundation for the main quality assurance mechanisms in any profession: accreditation, registration and advanced certification. Moreover, Untalan ${ }^{[6]}$ mentioned that professional standards for teaching include fulfilling the need for valid and nationally consistent standards and methods of teacher comparative evaluation for the development of career structures based on teaching expertise and for rewarding increases in quality of teaching and these standards are essential in building such competencies. Aguilar ${ }^{[7]}$ added that competent teachers are those who possess higher rank on teaching effectiveness, higher teaching experience and more exposure to professional growth activities.

In an analysis of science teaching, research found that teachers' coursework credits in science were not significantly related to student learning, but coursework in science education was significantly related to students' achievement on tasks requiring problem solving and applications of science knowledge. Teachers with greater training in science teaching were more likely to use laboratory techniques and discussions and to emphasize conceptual applications of ideas, while those with less education training placed more emphasis on memorization ${ }^{[8]}$. Montalbo ${ }^{[9]}$ disclosed that teachers need the following to enhance their competencies: orientation on the use of variety of teaching methodologies, enhancement of knowledge and skills in technological related aids (computers); and evidence-based activities such as in-service training. The study of Sagun ${ }^{[10]}$ recommended the continuance of the annual university and department-sponsored seminar workshops for faculty development. 


\section{CONCLUSION}

Based on the findings of the study it is concluded that a significant difference exists between the perceived mastery of students and the perceived competencies of the teachers in the different concepts of General Chemistry.

\section{REFERENCES}

[1] Ajayi, O. (2010). Teaching Practice Variables as Predictors of Attitude of Biology Teacher-Trainees to School Work. Department of Educational Foundations and Instructional Technology. Journal of Research in National Development. 8 (1)

[2] Ringer et al. (2010). Cultural Diversity in the Modern Tertiary Environment: The Role of Assessment and Learning Approaches. Journal of Research in National Development. 8 (3).

[3] Glass, G. \& and Smith, V. (2005).School class size: Research and Policy. Beverly Hills, CA: SAGE Publications, Research Document. Stanford University,

[4] Olatunde, P. (2009). Relationship Between Teachers' Attitude and Students' Academic Achievement in Mathematics in Some Selected Senior Secondary Schools in Southwestern Nigeria. European Journal of Social Sciences. 11 (3).

[5] De Chavez, A. (2001). The Morale and Instructional Performance of Teacher Educators in the Province of Batangas: Basis for the Development of a Proposed In-Service Program. Ph.D. Dissertation, Centro Escolar University.

[6] Untalan. S. (2010). Clinical Teaching and Support for Learners in the Practice Environment. Master's Thesis, Universidad de Sta. Isabel, Naga City. 73-74.

[7] Aguilar, E. (1997). The Effects of Selected Intellective and Non-Intellective Variables in the Teaching Competencies of College Physical Education Instructors in University Setting. Masters' Thesis, Centro Escolar University, Manila. 121.

[8] Haller. E. (2003). Teacher Characteristics and Gains in Student Achievement: Estimation Using Micro Data. The American Economic Review. Research Document. Stanford University

[9] Montalbo, J. (2007). Assessment of the Teaching Competencies of Elementary School Science Teachers: Basis of a Proposed In-Service Training Program. Masters' Thesis, Centro Escolar University. 77.

[10] Sagun, C. (1994). Teaching Competencies of Chemistry Instructors; Basis for In-Service Training Program. Master's Thesis. Centro Escolar University. 68.

Citation: Welyn Rentillo-Co. "Comparison of Students' Perceived Mastery and Teachers' Perceived Competencies in Different Concepts in General Chemistry." International Journal of Humanities Social Sciences and Education (IJHSSE), vol 4, no. 10, 2017, pp. 77-80. doi:http://dx.doi.org/10.20431/23490381.0410011 .

Copyright: () 2017 Authors. This is an open-access article distributed under the terms of the Creative Commons Attribution License, which permits unrestricted use, distribution, and reproduction in any medium, provided the original author and source are credited. 